ISSN 2145-6054

\title{
LAS COMISIONES DE LA VERDAD EN COLOMBIA ${ }^{1}$ Truth Commissions in Colombia
}

$\underline{\text { Gina María Kalach Torres }}^{2}$

Fecha de Recepción: 27 de abril de 2016

Fecha de Aceptación: 20 de mayo de 2016

SUMARIO: 1. Introducción; 2. Establecimiento y características de las Comisiones de la Verdad;

3. Comisiones de la Verdad en Colombia; 3.1Comisiones sobre violencia y conflicto armado;

3.1.1 Comisión Investigadora de las Causas de la Violencia; 3.1.2 Comisión de Estudios sobre la Violencia; 3.1.3 Comisión de Superación de la Violencia; 3.1.4 Comisión de Derechos Humanos para la Costa Atlántica; 3.1.5 Comisión Nacional de Derechos Humanos; 3.2 Comisiones para el análisis y resolución de casos concretos; 3.2.1 Caso Palacio de Justicia; 3.2.2 Caso Masacre de Trujillo; 3.3.3 Comité de impulso para la administración de justicia en relación con los hechos de Uvos, Caloto y Villatina; 3.3.4 Comisión para la Búsqueda de la Verdad y Comité Especial encargado de agilizar las investigaciones de derechos humanos en Barrancabermeja; 3.4 Comisión con carácter asesor: Comisión Nacional de Reparación y reconciliación - CNRR; 4. Conclusiones; 5. Referencias Bibliográficas.

\footnotetext{
${ }^{1}$ Este artículo es el resultado de un análisis efectuado por la autora en su tesis doctoral titulada: Le droit à réparation des victimes de violations graves et massives des droits de I'homme en Colombie. Universitè Paris I Panthèon Sorbonne, 2011.

${ }^{2}$ La autora es abogada egresada de la Universidad de Cartagena, con estudios de Maestría y Doctorado de la Universidad Sorbona de París. Fue responsable en diseño, seguimiento y evaluación de políticas públicas y asuntos internacionales en materia de derechos humanos del Ministerio del Interior. Ha desempeñado labores académicas y de investigación y de asesoría legal en la academia y en organismos internacionales de derechos humanos. Actualmente, es asesora en Naciones Unidas en Colombia.
} 


\section{CÓMO SE CITA ESTE ARTÍCULO (Normas APA-6)}

Kalach Torres, Gina María (2016). Las comisiones de la verdad en Colombia. Revista Jurídica Mario Alario D’Filippo, VIII (16), pág 106-124.

\section{RESUMEN}

En Colombia, varias Comisiones de la Verdad han sido creadas en diferentes estadios de la historia. En general, todas han tenido el mandato o misión común de contribuir al esclarecimiento sobre hechos de violencia o de violaciones a derechos humanos en favor del derecho a la verdad de las víctimas y de la sociedad. Estas Comisiones detentan la particularidad de haber nacido y desarrollado su labor durante contextos de violencia y de conflicto. Así, si bien algunas han surgido como resultado de procesos de negociaciones con grupos armados ilegales, estas negociaciones se han dado en medio de un conflicto subsistente. De esta forma, el texto presenta un análisis de las distintas Comisiones que ha tenido el país y para ello, propone una clasificación en distintas categorías según su naturaleza, rol, alcance y mandato. Como resultado de este estudio y categorización, y debido a distintas causas, se analiza su nivel de contribución a la búsqueda efectiva de justicia, verdad y de reparación de las víctimas. Lo anterior, brinda elementos de consideración y de lecciones aprendidas, para el trabajo de la Comisión creada en el actual Acuerdo de Paz entre las FARC-EP y el Gobierno nacional.

\section{PALABRAS CLAVE}

Comisiones de la Verdad, verdad, justicia, reparación, mandato, informes, recomendaciones, violencia, conflicto, víctimas, esclarecimiento.

\section{ABSTRACT}

In Colombia, many Truth Commissions have been created in different stages of history. They had contributed to the clarification of facts of violence and human rights violations regarding the right to the truth for victims and society as a whole. These Commissions have had the peculiarity of having been born and developed their work in a context of violence and armed conflict. In fact, even if some Commissions have emerged as a result of negotiations with illegal armed groups, these negotiations have taken place in the midst of conflict. This article presents an analysis of the different Commissions in Colombia and proposes a classification according to their nature, role, scope and mandate. This provides elements of consideration and lessons for the work of the Commission created as a result of the recent Peace Agreement between the FARC-EP and Colombian Government.

\section{KEYWORDS}

Truth Commissions, truth, justice, reparation, mandate, reports, recommendations, violence, conflict, victims, elucidation. 


\section{INTRODUCCIÓN}

Cuando las sociedades se encuentran en procesos de tránsito de un periodo de conflicto o de régimen autoritario o dictatorial a un periodo de paz o de democracia pueden crear medidas judiciales y políticas con el fin de dar respuesta a la pregunta sobre qué hacer con el legado de abusos que ha dejado la violencia y cómo lograr que los responsables de esos abusos contribuyan al establecimiento de un nuevo orden social, en paz, democrático y en un contexto de reconciliación y respeto. Lo anterior es lo que se conoce como justicia transicional ${ }^{3}$.

Para lograr un sano equilibrio de las demandas de paz y justicia propias de periodos de transición es necesario tomar medidas o crear mecanismos alternativos que permitan coadyuvar con estos propósitos, ya que las instituciones ordinaras o tradicionales de los Estados no son suficientes, capaces o no están habilitadas para dar respuesta a las múltiples y complejas exigencias de la transición. Algunos de esos mecanismos de justicia transicional pueden ser: programas de reparación, creación de tribunales especiales o de excepción que se especialicen en la investigación, sanción y juzgamiento o de las amnistías o indultos de los responsables de las violaciones cometidas, peticiones públicas de perdón, monumentos y conmemoraciones, desmovilización, desarme y reintegración y creación de Comisiones de la Verdad.

En Colombia se han creado diversas Comisiones de la Verdad (en adelante también CV o Comisiones).Aunque estas CV han sido creadas con diferentes características y objetivos, todas coinciden en tener como propósito, el establecimiento de la verdad sobre hechos de violencia, conflicto y/o violación de derechos humanos. No sin antes brindar elementos conceptuales de carácter general sobre las particularidades de estos Organismos, este artículo se concentra en el análisis de las Comisiones colombianas, y para comprenderlas mejor, propone una categorización según sus diferentes características, mandato, naturaleza y alcance.

\section{ESTABLECIMIENTO Y CARACTERÍSTICAS DE LAS COMISIONES DE LA VERDAD}

Las Comisiones de la Verdad son instrumentos de justicia de transición con los que cuenta una sociedad para hacer frente a una situación de graves y sistemáticas violaciones a los derechos humanos, en el tránsito desde una etapa de conflicto armado hacia la paz o hacia la democracia, si se ha superado, generalmente, una época de represión dictatorial ${ }^{4}$

\footnotetext{
${ }^{3}$ El término "justicia transicional" fue utilizado por primera vez por la doctrina anglosajona durante los años noventa por autores como Neil Kritz (1995), Martha Minow (1998) y Ruti Teitel (2000) Se consolidó internacionalmente en la primera década del siglo XX y desde allí la justicia transicional se ha convertido en una verdadera rama de estudio y hace parte de las agendas públicas de los Estados que atraviesan por procesos de transición a la paz o a la democracia. No obstante, la justicia transicional como práctica, tiene cronológicamente sus orígenes en los procesos de transformación socio política después de la segunda guerra mundial (Tribunales de Núremberg, 1947).

${ }^{4}$ Véase González, E. y Varney, H. (Ed.). (2013). En busca de la verdad. Elementos para la creación de una comisión de la verdad eficaz.
} 
Las Comisiones de la Verdad son organismos de investigación creados para ayudar a las sociedades que han enfrentado graves situaciones de violencia política o guerra interna a enfrentarse críticamente con su pasado, a fin de superar las profundas crisis y traumas generados por la violencia y evitar que tales hechos se repitan en el futuro cercano ${ }^{5}$.

Los objetivos del trabajo de CV son: 1) aclarar y dar a conocer la verdad, 2) responder a las necesidades e intereses de las víctimas, 3) contribuir al establecimiento de las responsabilidades de justicia y 4) promover la reconciliación. Cada uno de estos aspectos es, alternativamente, un recurso importante para las víctimas y sus seres como un proceso de curación completa que comienza por garantizar la verdad (Hayner, 2001, p. 24) Las CV pueden estar encargadas de esclarecer la verdad para investigar los crímenes y castigar a los responsables, de apoyar al sistema judicial penal en las investigaciones, juzgamiento y sanción de los responsables, de determinar responsabilidades institucionales, de contribuir con una indemnización integral, fomentar la reconciliación y contribuir con la elaboración de un diagnóstico completo sobre las causas de los conflictos y el diagnóstico para desarrollar estrategias con el fin de compensar a las víctimas y evitar que hechos similares se reproduzcan en el futuro (Springer,2012, p. 89).

Las Comisiones pueden contribuir a una transición a la paz o a la democracia en un ambiente de neutralidad y de imparcialidad. Estos órganos pueden facilitar y garantizar los derechos de las víctimas a la verdad, justicia y reparación. Las comisiones de la verdad son una herramienta poderosa e importante no sólo para el establecimiento de la verdad sobre los abusos del pasado, sino también para iniciar el cambio institucional necesario para evitar la repetición de los abusos. El éxito de sus acciones depende de las prerrogativas o facultades otorgadas al momento de su creación, rol, funciones, de la composición, neutralidad e imparcialidad de sus miembros, de los poderes otorgados, del presupuesto que le sea asignado y del respaldo estatal al momento de su creación, durante y al finalizar su gestión. Las características generales de las Comisiones de la Verdad las podemos señalar de la siguiente manera:

a) Son creadas mediante normas o como resultado de acuerdos de paz.

b) Tienen una duración determinada (uno o tres años en promedio) no son órganos permanentes pues no buscan reemplazar o sustituir la institucionalidad existente, aunque en algunos casos se han establecidos en contextos donde la justicia ha sido inoperante.

c) El objeto es develar la verdad, investigar, establecer registro histórico, evaluar, investigar, juzgar y efectuar recomendaciones violaciones a derechos humanos, hechos de violencia o abusos cometidos durante dictaduras, conflictos armados, o contextos de abusos por motivos políticos, religiosos, raciales, etc.

d) Tienen la misión de ejercer su trabajo sobre hechos acaecidos en un período

ICJT ( International Center of Transitional justice), pág.13.

${ }^{5}$ Más información en Cuya, E. (s.f). Las Comisiones de la Verdad en América Latina. Recuperado de: http://www.derechos.org/koaga/ iii/1/cuya.html 
determinado.

e) Deben ser ampliamente respetados por la sociedad y su neutralidad ha de ser aceptada por todas las partes de un conflicto previo. Puede incluir a profesionales de distintos ámbitos o trayectorias. Algunos países han decidido incluir a miembros internacionales. Las Comisiones de la Verdad pueden ser conformadas por personalidades reconocidas y respetadas del país, de distintos ámbitos del conocimiento.

f) Cumplen unas actividades: toma de declaraciones, creación de una base de datos, estudios de las causas de la violencia e investigaciones, audiencias públicas (Hayner, 2006).

g) Deben contar con financiación suficiente para el ejercicio de su labor (Oficina del Alto Comisionado de las Naciones Unidas, 2010).

h) Emiten recomendaciones, por lo general, a través de un informe final. Pueden sugerir reformas jurídicas, institucionales o legislativas para prevenir abusos futuros, un programa de reparación para las víctimas, o nuevas exhumaciones o investigaciones. También puede sugerir medidas complementarias específicas para garantizar la aplicación oportuna y efectiva de sus recomendaciones ${ }^{6}$.

\section{COMISIONES DE LA VERDAD EN COLOMBIA}

En los últimos sesenta años diversas Comisiones de la Verdad se han establecido en Colombia, las cuales clasificamos o categorizamos así: Comisiones sobre violencia y conflicto armado, Comisiones para el análisis y resolución de casos concretos, Comisión con carácter asesor: Comisión Nacional de Reparación y reconciliación - CNRR, Comisión fruto de un acuerdo de paz definitivo entre el Gobierno y las FARC-EP: La Comisión para el Esclarecimiento de la Verdad, la Convivencia y la No Repetición.

\subsection{COMISIONES SOBRE VIOLENCIA Y CONFLICTO ARMADO}

\subsubsection{Comisión Investigadora de las Causas de la Violencia}

La primera experiencia de Comisión de la Verdad en Colombia fue la Comisión Investigadora de las Causas de la Violencia creada por el General Rojas Pinilla mediante Decreto 0942 del 27 de mayo de 1958 después del período de La Violencia7 Estuvo compuesta por dos representantes de los partidos políticos tradicionales, los liberales y los conservadores, dos soldados y dos sacerdotes y fue dirigida por Otto Morales Benítez. El trabajo de esta Comisión fue reunir pruebas y datos en las zonas afectadas por la violencia con el objetivo

\footnotetext{
${ }^{6}$ Más información: Comisión de Derechos Humanos. (2005). El derecho a la verdad. [Resolución 2005/66]. Recuperado de: http:// ap.ohchr.org/documents/S/CHR/resolutions/E-CN_4-RES-2005-66.doc

${ }^{7}$ Periodo de confrontación entre los partidos liberal y conservador entre 1946 y 1960, con un saldo de aproximadamente 300000 en un país de 11 millones de habitantes. El asesinato de Jorge Eliécer Gaitán en 1948 incrementó el nivel de violencia o para otros fue el inicio de este periodo. No hay acuerdo sobre la hora exacta del comienzo y el final de La Violencia y sus causas. Para algunos analistas, la Violencia comienza con el asesinato de Jorge Gaitán Eliécer en 1948 o en 1946 con el regreso de los conservadores al poder. Del mismo modo, su final es confuso, o en 1958 con el Frente Nacional, o en 1953 con el golpe de Rojas Pinilla o en 1965, con la expansión del Frente Nacional. Ver: Sánchez, G. (1988). Guerra y política en la sociedad colombiana. El Ancora Editores.
} 
de identificar las causas de la violencia y lograr desactivarlas. De acuerdo con uno de los miembros, la Comisión hizo un trabajo muy positivo para obtener la pacificación de algunas regiones y en la recogida del material que se utilizó para escribir un libro titulado La Violencia en Colombia (Guzmán, 1998).

\subsubsection{Comisión de estudios sobre la violencia}

En 1987, bajo la administración del presidente Virgilio Barco, se creó una Comisión denominada Comisión de Estudios sobre la Violencia conformada por diez especialistas académicos. La función y objetivo de la Comisión fue dar cuenta de las diferentes formas de violencia y generar recomendaciones para dar tratamiento, fundamentalmente político al conflicto, en un ambiente donde adquiría gran interés la búsqueda de la paz negociada. A diferencia de la Comisión precedente que estuvo más que todo conformada por personalidades de las élites políticas y sociales, esta Comisión estuvo conformada por expertos en temas de violencia ${ }^{8}$.

La Comisión emitió un informe titulado "Colombia: Violencia y Democracia" (1987) el cual analizó la compleja dinámica de la violencia y el conflicto y formuló recomendaciones en materia de violencia urbana, violencia política, violencia organizada, violencia contra minorías étnicas, violencia y medios de comunicación, conflictos sociales y regionales, criminalidad, impunidad y justicia, política internacional y pacificación nacional. Este informe fue considerado por la academia colombiana como el "primer gran diagnóstico de las violencias contemporáneas" (Jaramillo, 2011) El informe desarrolla la tesis de una "cultura de la violencia" por unos espirales de violencia que de generación en generación han vendido ascendiendo".

\subsubsection{Comisión de Superación de la Violencia}

En 1991 se creó la Comisión de Superación de la Violencia después de la firma de acuerdos de paz entre el Gobierno nacional y la guerrilla EPL y el Movimiento Quintín Lame. Esta Comisión recibió el mandato de llevar a cabo una revisión de las causas de la violencia y de preparar un informe después de las negociaciones de paz, con énfasis en la reinserción a la vida civil de los excombatientes. Su informe final fue nombrado "Pacificar la Paz" ${ }^{9} \mathrm{Se}$ integró con personas de reconocida trayectoria académica en el campo de los derechos humanos designadas por consenso en la comisión bilateral Gobierno-EPL ${ }^{10}$ Trabajó durante seis meses con autonomía, contó con un equipo de apoyo, se desplazó hacia

\footnotetext{
${ }^{8}$ En información aportada por Jaramillo Marín, J. (2011) la comisión estaba compuesta por Gonzalo Sánchez (Coordinador), Eduardo Pizarro, Álvaro Guzmán Barney entre otros.

${ }^{9}$ Comisión de Superación de la Violencia. (1992). Pacificar la Paz. Bogotá: Ed. Instituto de Estudios Políticos y Relaciones Internacionales de la Universidad Nacional/CINEP/Comisión Andina de Juristas Seccional Colombiana/CECOIN. p. 169.

${ }^{10}$ La Comisión de Superación de la Violencia estuvo integrada por Alejando Reyes (coordinador) y Eduardo Pizarro, del IEPRI de la UN; Francisco de Roux, del Cinep; Gustavo Gallón, de la Comisión Andina de Juristas; Eduardo Díaz y Roque Roldán, investigador de Cecoin. Olga Cecilia Pinilla fue su directora ejecutiva y contó con un equipo de apoyo profesional contratado.
} 
distintas regiones ${ }^{11}$ y aclimató el entendimiento. Realizó diagnósticos, prestó especial atención al tema del paramilitarismo, realizó talleres y foros y produjo un informe con recomendaciones del orden nacional y regional ${ }^{12}$.

El informe de la Comisión reconoció el aporte de las negociaciones de paz por la superación de la violencia, pero advirtió que su alcance era reducido sino se acompañaba de estrategias y acciones diversas desde el Estado y las autoridades de distinto orden. Demandó compromisos con las guerrillas no comprometidas en estos acuerdos, el tratamiento del narcotráfico, la disolución de los paramilitares y la terminación de las actuaciones ilegales de los agentes estatales. Dentro de las principales conclusiones, propuso una metodología para fortalecer la participación de la sociedad civil en la resolución de conflictos y la búsqueda de la paz. Las recomendaciones incluyeron políticas con el fin de mantener las conversaciones de paz con los movimientos guerrilleros activos, definir una política que posibilitara los diálogos regionales de paz, que elevara el rango y los poderes del programa de reinserción y que reorienta recursos del PNR hacia la consolidación de la paz en las regiones, con participación de los grupos humanos afectados y los desplazados. En él se propuso también intensificar los esfuerzos para superar la violencia asociada al narcotráfico y a los conflictos de tierras que afectan a las comunidades.

Las recomendaciones en derechos humanos demandaron superar la ineficacia y la impunidad mediante una justicia garantista y civilista, superar la interpretación laxa de la noción de fuero militar y promover el diálogo con la población en materia de seguridad. También propusieron conseguir el respeto del derecho internacional humanitario en las zonas de conflicto y crear comités de derechos humanos locales y regionales. Los resultados de la Comisión de Superación de la Violencia fueron entregados al Gobierno nacional, a los voceros nacionales del EPL y del Quintín Lame y publicados. Sin embargo, nunca hubo una respuesta oficial y las recomendaciones como tal no fueron adoptadas por el Gobierno nacional ${ }^{13}$.

\subsubsection{Comisión de derechos humanos para la Costa Atlántica}

El acuerdo final de paz entre el Gobierno y el Partido Revolucionario de Trabajadores - PRT, convino crear una Oficina Delegada para la Costa Atlántica de la Consejería Presidencial de Derechos Humanos y una Comisión Gubernamental para los Derechos Humanos

\footnotetext{
${ }^{11}$ La comisión actuó en Norte de Santander, Córdoba, Urabá, Noroccldente de Antioquia, Risaralda, Putumayo y Cauca; reunió ex combatientes guerrilleros, Fuerzas Armadas, organismos de seguridad, autoridades civiles, funcionarios públicos, gremios, organizaciones campesinas, Indígenas, representantes de distintas ONG, de la Iglesia católica y otros sectores.

${ }^{12}$ Comisión de Superación de la Violencia. (1992). Pacificar la paz: lo que no se ha negociado en los acuerdos de paz. Recuperado de: http://observatorioetnicocecoin.org.co/cecoin/files/pacificar_la_paz.pdf

13 Villarraga Sarmiento, A. (s.f) Posibilidades de una comisión de verdad. Recuperado de: https://www. google.com.co/url? sa =t\& $r c t=j \& q=\& e s r c=s \& s o u r c e=w e b \& c d=1 \& c a d=r j a \& u a c t=8 \& v e d=0$ ahUKEwjGzOPEDTA hWEeCYKHZPwCQAQFggkMAA\&url=http\%3A\%2F\%2Fw1.cejamericas.org\%2Findex. php\%2Fbiblioteca\%2Fbiblioteca-virtual\%2Fdoc_view\%2F2663-posibilidades-de-una-comisi\%25C3\%25B3n-de-la-verdad. html\&usg=AFQjCNEdcaVAtuRxolmw9W1ZPXZ2qOG_Jw
} 
en la Costa Atlántica, integrada por los gobernadores, las procuradurías, delegados de los personeros municipales, la Policía Nacional y las Fuerzas Militares, la Conferencia Episcopal y las organizaciones de derechos humanos.

El propósito de la Comisión de Derechos Humanos de la Costa Atlántica fue facilitar el conocimiento del tema y de la problemática de derechos humanos en esa región, elaborar informes, conseguir la participación de las organizaciones sociales y las comunidades, realizar campañas de formación, promoción y defensa, coadyuvar en el funcionamiento de los mecanismos legales, en la actuación de los entes estatales y en los mecanismos conciliatorios. Las acciones se focalizaron principalmente en las áreas de impacto directo de este pacto de paz. Precisamente, en la región de los Montes de María.

El Gobierno nacional creó esta Comisión mediante el Decreto presidencial 1078 de 1991, que especifica su composición y funciones al tenor de lo acordado. En su funcionamiento contó con la participación de las gobernaciones, la asesoría de la Consejería Presidencial para los Derechos Humanos y la participación de CORPADEC ${ }^{14}$.

La Comisión trabajó entre 1991 y 1992, luego, por carencia de apoyo institucional y por el resurgimiento de violaciones a los derechos humanos, suspendió labores para reanudarlas en 1994, a partir de un nuevo consenso conseguido con los movimientos amnistiados. A pesar de estas dificultades desarrolló programas, campañas, foros de sensibilización, talleres y coordinó actividades con distintas instituciones (Jaramillo,2011b).

En general se constató la persistencia de un clima de violaciones a los derechos humanos y al derecho internacional humanitario. Fue notoria la reactivación de la violencia en el campo, la inseguridad en las ciudades, y en varios departamentos, la ocurrencia de crímenes cometidos contra los ex combatientes y los promotores de proyectos sociales, cívicos y políticos relacionados con los procesos de paz (Villarraga Sarmiento).

\subsubsection{La Comisión Nacional de Derechos Humanos}

El acuerdo de paz con la Corriente de Renovación Socialista comprometió la realización en Bogotá, en 1994, de un foro nacional sobre la situación de derechos humanos ${ }^{15}$ Este foro destacó los temas de política de paz, impunidad y protección de los derechos humanos y posibilitó la creación mediante el Decreto 1533 de 1994, de la Comisión Nacional de Derechos Humanos. Esta Comisión emprendió un trabajo concertado sin precedentes, para darle continuidad y seguimiento a los trabajos del mismo foro ${ }^{16}$

\footnotetext{
${ }^{14}$ Corpadec es la fundación responsable de asesorar y asistir los programas de reinserción del PRT.

15 “Foro Nacional de Derechos Humanos, Retos y Propuestas" realizado en Bogotá el 21 y 22 de julio de ese año con participación nacional y asistencia del ministro gobierno y otras entidades gubernamentales, los organismos de control, la Defensoría del Pueblo, La Fuerza Pública, el Congreso de la República, la Cruz Roja Colombiana, el CICR y una nutrida delegación de organizaciones sociales y entidades de derechos humanos.

${ }^{16}$ La Comisión Nacional de Derechos Humanos se instaló el 23 de agosto de 1994 con participación permanente del ministro de gobierno Horacio Serpa, del consejero presidencial para los DDHH, Carlos Vicente de Roux, de otros delegados gubernamentales, de oficiales de alto rango de todas las ramas de la Fuerza Pública, de los organismos de control, la Defensoría del Pueblo, la Iglesia
} 
A raíz de la declaratoria de la conmoción interior por parte del entonces presidente Ernesto Samper en agosto de 1995 y de la expedición de decretos de orden público derivados de esta medida, como fue el de creación de las "zonas de orden público", se produjeron fuertes disensos y surgió la oposición de las organizaciones sociales a tales medidas. Esto, sumado al desgaste producido por un buen ejercicio de concertación pero que en medio de una difícil problemática de derechos humanos no repercutía en la toma de medidas y correcciones prontas y de fondo por parte del Gobierno, implicó el retiro de todas las delegaciones civiles. Esto significó en la práctica la disolución de los trabajos de la Comisión. Aunque no generó informe alguno, permitió la discusión en temas de derechos humanos, libertades públicas, reforma penal militar, acuerdos humanitarios y reforma agraria (Villarraga Sarmiento).

\subsection{COMISIONES PARA EL ANÁLISIS Y RESOLUCIÓN DE CASOS CONCRETOS}

\subsubsection{Caso Palacio de Justicia}

Este caso ha dado lugar a la creación de dos Comisiones. La primera Comisión fue denominada Tribunal Especial a los hechos del Palacio de Justicia. Fue creada con el fin de investigar los hechos que ocurrieron en la toma del Palacio de Justicia por la guerrilla del M-19. Esta Comisión fue creada por decreto presidencial por un período de tres meses, y los miembros fueron designados por la Corte Suprema de Justicia. Su función fue la de dirigir y coordinar las investigaciones realizadas por los Juzgados Penales. Esta Comisión emitió un informe que no logró los impactos esperados y según algunas organizaciones de derechos humanos, no sólo no contribuyó a la búsqueda de la verdad ni a la determinación de responsables, sino que legitimó los actos cometidos por Ejército (CAJAR, 2005, p. 323- 340).

La segunda Comisión denominada Comisión de la verdad sobre los hechos del Palacio de Justicia fue creada en 2005 por la Corte Suprema de Justicia. Su mandato principal fue explicar los hechos de la toma del Palacio de Justicia mediante la emisión de un informe final que se haría público para satisfacer la demanda por el derecho a la verdad de las víctimas. En 2006 presentó un informe preliminar de los hechos y luego, en 2007, un nuevo informe en forma de documental. A través de su informe final, publicado en 2008, la Comisión explicó los antecedentes, motivaciones y el contexto socio-político que rodeó la toma del Palacio, estableció un registro claro de los hechos y de todos los procedimientos judiciales iniciados por los familiares de las víctimas desaparecidas, así como las responsabilidades de la guerrilla del M-19, del Gobierno y de los militares. ${ }^{17}$

\footnotetext{
Católica, el CICR, la Cruz Roja Colombiana, las entidades de derechos humanos más reconocidas y los delegados de la Corriente de Renovación Socialista, quienes en conjunto con el ministro y el consejero conformaron el Comité Ejecutivo. Posteriormente, se aprobó el ingreso de otras entidades como el Departamento Nacional de Planeación, la CUT, Fundación Progresar, Cedavida y la Corporación Región.

${ }^{17}$ Gómez Gallego, J., Herrera Vergara, J., Pinilla Pinilla, N. (2010). Informe final de la Comisión de la Verdad sobre los hechos del Palacio de Justicia. Colección textos de jurisprudencia. Universidad del Rosario. Recuperado en: http://repository.urosario.edu.co/bitstream/ handle/10336/8792/Informe_comision_web.pdf?sequence=1
} 
Esta Comisión formuló recomendaciones sobre el derecho a la verdad, la justicia y otras medidas de reparación. Recomendó la indemnización a las familias de las víctimas muertas y desaparecidas, el establecimiento de medidas psicológicas de rehabilitación, el reconocimiento público de la responsabilidad y de perdón, actos de conmemoración, de clarificación de hechos, medidas para la determinación de responsabilidades penales, para la identificación y búsqueda de los restos, así como la aplicación garantías de no repetición. La Comisión continúa haciendo seguimiento a las recomendaciones y a los procesos judiciales.

\subsubsection{Caso Masacre de Trujillo}

La Comisión de investigación de los sucesos violentos de Trujillo fue creada para investigar las graves violaciones cometidas en el municipio de Trujillo-Valle. En este municipio alrededor de 342 personas fueron víctimas de tortura, de desapariciones forzadas o asesinatos entre 1988 y 1994 por grupos paramilitares y agentes estatales. Estas violaciones fueron sometidas a la Comisión Interamericana de Derechos Humanos, que abrió el proceso No. 11007 conforme al artículo 48 de la Convención Americana de los Derechos Humanos. La Comisión Interamericana de Derechos Humanos (CIDH) se puso a disposición de las partes para llegar a una solución amistosa.

La propuesta fue bien recibida por los solicitantes y en el 87으 período de sesiones de la Comisión Interamericana, el acuerdo se formalizó en un memorando de entendimiento que dio lugar, tras la propuesta del Gobierno, a la creación de una Comisión de Investigación ad hoc. De este modo, se crea esta Comisión y se compone de miembros del Gobierno, de la Iglesia Católica y de la sociedad civil. ${ }^{18}$

Tuvo las siguientes funciones: 1) revisar todos los registros legales, disciplinarios y administrativos sobre las investigaciones de los hechos para evaluar cuidadosamente el alcance de pruebas aportadas, 2) realizar entrevistas con testigos, 3) promover y garantía adopción de medidas de protección de testigos, 4) hacer recomendaciones a los órganos de justicia para guiar y acelerar el curso de las investigaciones judiciales, disciplinarias o administrativas y así evitar la impunidad, 5) hacer una evaluación de toda las pruebas recaudadas y establecer los elementos para la acusación o la absolución de los acusados o para determinar la responsabilidad del Estado en los hechos, y 6) hacer recomendaciones detalladas al Gobierno Nacional para la indemnización, restitución de los derechos de las víctimas. ${ }^{19}$

\footnotetext{
${ }^{18}$ Estuvo conformada por el Defensor del Pueblo, representantes del Senado de la República de la Procuraduría General de la Nación, el Consejo Presidencial para los Derechos Humanos, Ministro de Interior, de Relaciones Exteriores, de Defensa Nacional, Departamento Administrativo de Seguridad, el Inspector general de las Fuerzas Armadas y la Policía nacional, la Comisión de Justicia y Paz, la Cruz Roja, ASFADDES CCAJAR, Comisión Andina de Juristas y la Fundación Comité de Solidaridad con los Presos Políticos.

${ }^{19}$ Presidencia de la República. (18 de julio de 1994). Se crea la Comisión de Derechos Humanos adscrita al Departamento Administrativo de la Presidencia de la República y se asignan algunas funciones. [Decreto 1533 de 1994].
} 
Esta Comisión elaboró un informe detallado sobre la responsabilidad del Estado colombiano por acciones y omisiones de sus agentes en los hechos. Se pronunció sobre la responsabilidad individual de un oficial general y estableció la responsabilidad de las instituciones judiciales. Por lo tanto, la Comisión afirma que tienen "muchos elementos de evidencia que sugiere que los miembros del poder judicial responsables de la investigación y el enjuiciamiento de los hechos de Trujillo se abstuvieron de reunir pruebas importantes, juzgaron el caso en contra de la realidad y cometieron otras irregularidades procesales que impidieron la identificación y sanción de los responsables". ${ }^{20}$

Con el fin de reparar moralmente y socialmente a la comunidad Trujillo y la sociedad colombiana, la Comisión recomendó al Gobierno desarrollar un vasto programa de inversión social en la zona, hacer un reconocimiento público y simbólico de sus responsabilidades, publicar el informe, difundir un resumen de los hechos, de las conclusiones y recomendaciones en la prensa y, construir un monumento en memoria de las víctimas ${ }^{21}$ La Comisión Interamericana resolvió que el Estado colombiano debía evaluar y adoptar las conclusiones y recomendaciones formuladas en el informe en Trujillo. Los resultados no fueron los mejores porque las acciones de reparaciones recomendadas fueron poco ejecutadas y se caracterizaron por el uso de los recursos económicos de manera ineficiente por parte del gobierno local y por la falta de programas para las víctimas ${ }^{22}$ En 2016 se firmó un nuevo acuerdo de solución amistosa con el Estado colombiano y los representantes de las víctimas, a instancias de la $\mathrm{CIDH}$ en periodo de sesiones.

\subsubsection{Comité de impulso para la administración de justicia en relación con los hechos de Uvos, Caloto y Villatina}

Fue creado para contribuir a la justicia y la verdad de las masacres cometidas en esos municipios. De hecho, en 1995, la CIDH estudió los casos de homicidios cometidos, al parecer, por agentes del Estado y grupos paramilitares en los municipios de Caloto, Villatina y Los Uvos. La Comisión instó al Estado colombiano y representantes de las víctimas a una solución amistosa en estos casos. El 7 de septiembre 1995 los representantes de las víctimas y del Gobierno llegaron a un acuerdo sobre la creación de una comisión para contribuir a la eficacia de las investigaciones. El Comité fue creado por Decreto y estuvo conformado por funcionarios del Estado y representantes de las víctimas ${ }^{23}$ Tenía las facultades de contribuir a investigaciones judiciales y disciplinarias eficaces y ágiles, a la identificación de las pruebas pertinentes para el juicio, para promover la protección de

\footnotetext{
${ }^{20}$ Comisión de Investigacion de los Sucesos Violentos de Trujillo. (1995). Informe Final. Caso No. 11.007 de la Comisión Interamericana de Derechos Humanos.

21 Ibidem.

${ }^{22}$ Memoria Histórica de la Comisión Nacional de Reparación y Reconciliación. (2008). Trujillo, una tragedia que no cesa. Recuperado de: https://www.centrodememoriahistorica.gov.co/descargas/informes2008/informe_trujillo.pdf

${ }^{23}$ Presidencia de la República. (15 de febrero de 1996). Se crea el Comité de impulso para la administración de justicia en relación con los hechos de Uvos, Caloto y Villatina. [Decreto 0318 del 15 de febrero de 1996].
} 
los testigos y miembros del poder judicial que participan en las investigaciones y asegurar la indemnización.

El Comité celebró sesiones durante varios meses y presentó su informe a la Comisión Interamericana. Sin embargo, sólo el caso de la masacre de Villatina se resolvió a través de una solución amistosa. Los casos de Caloto y Uvos siguieron el procedimiento normal ante la Comisión Interamericana, que finalmente declaró la responsabilidad del Estado por las violaciones. ${ }^{24}$

\subsubsection{Comisión para la Búsqueda de la Verdad y Comité Especial encargado de agilizar las investigaciones de derechos humanos en Barrancabermeja}

Como consecuencia del asesinato de once personas y la desaparición forzada de 25 personas en la ciudad de Barrancabermeja el Gobierno creó la Comisión para la Búsqueda de la Verdad y Comité Especial encargado de agilizar las investigaciones de derechos humanos en Barrancabermeja. Esta Comisión fue responsable, en particular, de "proporcionar información a las instituciones de investigación y sanción del Estado para orientar y agilizar las investigaciones penales, judiciales, disciplinarias y las medidas administrativas para garantizar que los hechos no queden en la impunidad"25. Como resultados de su trabajo, se adelantaron algunas acciones judiciales sin mayor éxito ${ }^{26}$. Esta Comisión no logró los resultados esperados. Su informe no se hizo público. En cuanto al Comité Especial, un informe de la Oficina de la Alta Comisionada de las Naciones Unidas declaró que este Comité sólo se había reunido dos veces y fue difícil una acción efectiva de este órgano cuando sólo tenía objetivos operativos. El Comité se limitó a analizar las dificultades de los procesos sin que esta evaluación se tradujera en resultados concretos para superar las dificultades ${ }^{27}$.

\subsection{COMISIÓN CON CARÁCTER ASESOR: COMISIÓN NACIONAL DE REPARACIÓN Y RECONCILIACIÓN - CNRR}

El artículo 50 de la Ley 975 ordenó la creación de la Comisión Nacional de Reparación y Reconciliación. Las funciones de la CNRR fueron, entre otras: garantizar los derechos de las víctimas que participan en el proceso de esclarecimiento judicial, informar públicamente

\footnotetext{
${ }^{24}$ Véase CIDH. (2000) Informe № 35/00. Caso 11.020. Masacre "Los Uvos", Colombia. Recuperado de: https://www.cidh.oas.org/ annualrep/99span/De\%20Fondo/Colombia11020.htm y CIDH. (2000). Informe № 36/00. Caso 11.101. Masacre "Caloto", Colombia. Recuperado de: https://www.cidh.oas.org/Indigenas/Colombia.11.101.htm

${ }^{25}$ Presidencia de la República. (4 de junio de 1998). Se crea la Comisión para la Búsqueda de la Verdad. [Decreto 1015 de 1998].

${ }^{26}$ La Procuraduría General investigó a ocho soldados involucrados en la masacre, tres soldados fueron absueltos y los otros fueron suspendidos. El 12 de agosto 1998, la Fiscalía General de la Nación decidió la detención preventiva de un soldado del ejército por el delito de homicidio con circunstancias agravantes y secuestro. Pero en 1999, fue absuelto. En 2005, tres paramilitares responsables de estos crímenes habían solicitado ser juzgados por la ley de justicia y paz. Ver Comision Intereclesial de Justicia y Paz. (2009). Masacre del 16 de mayo de 1998 en Barrancabermeja, 11 años de Impunidad. Informe No. 159. Recuperado de : http://www.anarkismo.net/ article/13150

${ }^{27}$ Alto Comisionado de las Naciones Unidas para los Derechos Humanos .(2000). Informe sobre la situación de Derechos Humanos en Colombia. E/CN.4/2001/15, 20 de marzo de 2001, párrafo 208.
} 
sobre las razones para el surgimiento y evolución de grupos armados ilegales, realizar un seguimiento del proceso de desmovilización de los grupos armados organizados al margen de la ley, supervisar y evaluar periódicamente la reparación, indicar las recomendaciones para una compensación adecuada, poner en práctica la acción nacional de reconciliación y prevenir la reaparición de nuevos actos de violencia.

La CNRR estuvo constituida por trece miembros de los cuales cuatro personas eran funcionarios del Gobierno, cinco fueron nombrados directamente por el Presidente de la República y tres eran miembros de la sociedad civil. De lo anterior se evidencia que el número de personas nombradas por el Gobierno es bastante alto: de trece miembros, nueve dependen directamente del Presidente lo cual va en contra de los principios de independencia y autonomía que deben tener estas Comisiones. ${ }^{28}$

Esta CV fue más que todo un órgano consultivo creado por el Estado. Su naturaleza principalmente gubernamental sería una muestra de una falta de imparcialidad e independencia. La CNRR tuvo un carácter ambiguo que le valió fuertes críticas. Por un lado, se generó gran entusiasmo y optimismo entre algunos sectores por su nombre atractivo y sus funciones. Por otra parte, según organizaciones de derechos humanos, la CNRR no cumplió su función como garante de los derechos de las víctimas ${ }^{29}$ Según otros analistas, sus acciones en materia verdad y de esclarecimiento y búsqueda de reparaciones a las víctimas no fueron claras. No realizó un trabajo real de comunicación, sensibilización ni de información objetiva a la sociedad, ni guio un proceso de reparación en un contexto de reconciliación colectiva. ${ }^{30}$

\subsection{COMISIÓN FRUTO DE UN ACUERDO DE PAZ DEFINITIVO ENTRE EL GOBIERNO Y LAS FARC-EP: LA COMISIÓN PARA EL ESCLARECIMIENTO DE LA VERDAD, LA CONVIVENCIA Y LA NO REPETICIÓN}

En noviembre del 2016, y como resultado del acuerdo definitivo entra las FARC - EP y el Gobierno nacional, se crea la Comisión para el Esclarecimiento de la Verdad, la Convivencia y la No Repetición. Esta CV tiene más características propias de las Comisiones de la Verdad, aunque expresamente se eliminó toda vinculación o relación con el poder judicial. Por lo tanto, no podrá presentar información que pueda ser relevante para los tribunales y mucho menos remitir nombres de los responsables para su investigación e enjuiciamiento.

\footnotetext{
${ }^{28}$ Conforme al Conjunto de principios para la protección y la promoción de los derechos humanos mediante la lucha contra la impunidad, las comisiones de investigación, incluidas las comisiones de la verdad, deben establecerse mediante procedimientos que garanticen su independencia, imparcialidad y competencia. En la mayor medida posible, las decisiones de establecer una comisión de la verdad, definir su mandato y determinar su composición deben basarse en amplias consultas públicas en las cuales deber requerirse la opinión de las víctimas y los supervivientes. Véase Comisión de Derechos Humanos (2005). Conjunto de principios actualizado para la protección y la promoción de los derechos humanos mediante la lucha contra la impunidad, Principios 6-7.

${ }^{29}$ Giraldo, G. G. (2006). La CNRR : ¿ Dr. Jekyll o Mr. Hyde? Por una comisión que contribuya a la efectiva reparación de los derechos de las víctimas de crímenes de guerra y de lesa humanidad en Colombia. Pensamiento Jurídico, (17), 127-146.

${ }^{30}$ Bonilla, M. E. (2008). La Comisión fantasma. Recuperado de: http://www.elespectador.com/opinion/la-comision-fantasmacolumna-21553
} 
Desde el Acuerdo de Paz se dejan estipulados los aspectos relacionados con su mandato, periodo de duración, naturaleza (órgano extrajudicial), funciones, composición de sus miembros, financiación, periodo de su objeto de estudio, la elaboración de informe con recomendaciones. Estos aspectos son los contenidos básicos que se deben estipular para una Comisión de la Verdad y son:

a) Cuenta con un mandato claro que le permitirá de manera general: 1) aclarar y dar a conocer la verdad, 2) contribuir al establecimiento de responsabilidades en el conflicto y 3) promover la reconciliación. Podrá ejercer sus funciones más específicas relacionadas con investigaciones y estudios sobre las violaciones a los derechos humanos e infracciones al derecho internacional humanitario, impacto del conflicto armado, fenómeno de violencia y paramilitarismo. Para ello tendrá facultad para: establecer una metodología, tomar de declaraciones, realizar audiencias públicas temáticas, territoriales, institucionales y de organizaciones, orientar a las víctimas, adoptar medidas de archivo, elaborar un informe final con sus recomendaciones.

b) Tiene una duración determinada (tres años). No es un órgano permanente y no busca reemplazar o sustituir la institucionalidad existente.

c) Se establece como un mecanismo extrajudicial, independiente e imparcial.

d) Sus objetivos fundamentales son tres: búsqueda y esclarecimiento de la verdad, promover el reconocimiento de las víctimas y de las responsabilidades, así como la convivencia en los territorios y garantizar la no repetición. También contribuirá a la construcción de la paz y promoverá un ambiente de diálogo con enfoque territorial, diferencial y de género.

e) Tiene la misión de ejercer su objeto sobre hechos acaecidos en un período determinado (el periodo del conflicto armado en Colombia).

f) Busca garantizar la independencia, idoneidad e imparcialidad de los 11 miembros que la conformarán, de forma que sean ampliamente respetados por la sociedad y que su neutralidad sea aceptada por todas las partes.

g) Se estipula el compromiso que contará con suficiente financiación.

h) Emitirá un informe final con unas recomendaciones. El Informe de la Comisión será presentado de manera oficial mediante acto público a las ramas del poder público y al conjunto de la sociedad.

i) Se estipula la creación de una comisión de seguimiento a las recomendaciones que sean formuladas por la $\mathrm{CV}^{31}$.

\section{CONCLUSIONES}

Las Comisiones de la Verdad en Colombia han sido creadas para dilucidar los fenómenos de violencia y contribuir a la persecución y reparación de violaciones de los derechos humanos, pero estos organismos no han ayudado plenamente en ese propósito. En

\footnotetext{
${ }^{31}$ Véase Presidencia de la República. (5 de abril del 2017). Se organiza la Comisión para el Esclarecimiento de la Verdad, la Convivencia y la no Repetición. [Decreto 588 de 2017].
} 
primer lugar, algunas han tenido funciones algo fragmentadas y limitadas (Comisiones para casos concretos). Otras han tenido objetivos demasiado vastos o contextuales (Comisiones para el análisis de la violencia o el conflicto armado). En ambos casos, los esfuerzos serían inútiles porque la verdad tiende a ser incompleta. En segundo lugar, en su mayoría, estas Comisiones han sido creadas con alta participación del Gobierno y con poca participación de los miembros de la sociedad civil. Esto es contrario a los principios de la creación de una comisión cuando el éxito, la legitimidad, la independencia y la autonomía de una comisión dependen en gran medida de la participación plena e igualitaria de las distintas fuerzas sociales, nacionales e internacionales.

Por otro lado, casi toda las CV han tenido una posición académica, histórica o informativa y sus informes no han contado con un impacto social y jurídico importante. Además, se han creado durante el conflicto, lo que ha dado lugar a un funcionamiento complejo respecto a su papel, mandato o éxito de su labor y sus resultados.

Pese a lo anterior, la Comisión para el Esclarecimiento de la Verdad, la Convivencia y la No Repetición cumple con mejores condiciones para lograr ser una Comisión de la Verdad con un más alto alcance e impacto social. La preponderancia del mecanismo bajo el cual fue creada (Acuerdo de paz definitivo), así como las características señaladas en ese mecanismo, amplitud de su mandato, periodo de duración, naturaleza, funciones, composición de sus miembros, financiación, periodo de su objeto de estudio, elaboración de informe con recomendaciones, le brindan mayores posibilidades de convertirse en un órgano autónomo e independiente, con facultades para garantizar que el éxito de su operación esté al nivel de las expectativas que se han fundado en el país con su creación y se pueda así contribuir con el establecimiento de la verdad para las víctimas y la sociedad en general.

\section{REFERENCIAS BIBLIOGRÁFICAS}

Alto Comisionado de las Naciones Unidas para los Derechos Humanos .(2000). Informe sobre la situación de Derechos Humanos en Colombia. E/CN.4/2001/15, 20 de marzo de 2001, párrafo 208. Alto Comisionado de las Naciones Unidas para los Derechos Humanos.(2000). Informe sobre la situación de Derechos Humanos en Colombia.

Bonilla, M. E. (2008). La Comisión fantasma. Recuperado de: http://www.elespectador. com/opinion/la-comision-fantasma-columna-21553

Colectivo de Abogados Jose Alvear Restrepo- CAJAR. (2005). Redes de esperanza tejidas con memoria. Verdad, justicia y reparación diciembre de 2005, bogotà 
Comisión de Derechos Humanos. (2005). El derecho a la verdad. [Resolución 2005/66]. Recuperado de: http://ap.ohchr.org/documents/S/CHR/resolutions/E-CN_4RES-2005-66.doc

- (2005). Conjunto de principios actualizado para la protección y la promoción de los derechos humanos mediante la lucha contra la impunidad. Recuperado de: http:// www.derechos.org/nizkor/impu/impuppos.html

Comisión de Estudios sobre la violencia. (1987). Colombia: Violencia y democracia Bogotá: Universidad Nacional de Colombia.

Comisión de Investigacion de los Sucesos Violentos de Trujillo. (1995). Informe Final. Caso No. 11.007 de la Comisión Interamericana de Derechos Humanos.

Comisión de Superación de la Violencia. (1992). Pacificar la Paz. Bogotá: Ed. Instituto de Estudios Políticos y Relaciones Internacionales de la Universidad Nacional/CINEP/ Comisión Andina de Juristas Seccional Colombiana/CECOIN.

Comisión Interamericana de Derechos Humanos. (1994). Proceso No. 11007. Recuperado de: http://www.hchr.org.co/documentoseinformes/documentos/html/informes/osi/cidh/ CIDH\%20Informe\%20Anual\%201994\%200\%200EA-SER-L-V-II-88-DOC-9.html

. (2000) Informe № 35/00. Caso 11.020. Masacre «Los Uvos», Colombia. Recuperado de: https://www.cidh.oas.org/annualrep/99span/De\%20Fondo/Colombia11020.htm

. (2000). Informe № 36/00. Caso 11.101. Masacre "Caloto", Colombia. Recuperado de: https://www.cidh.oas.org/Indigenas/Colombia.11.101.htm

Comision Intereclesial de Justicia y Paz. (2009). Masacre del 16 de mayo de 1998 en Barrancabermeja, 11 años de Impunidad. Informe No. 159. Recuperado de : http:// www.anarkismo.net/article/13150

Conferencia Especializada Interamericana sobre Derechos Humanos. (1969). Convención Americana sobre Derechos Humanos. Recuperado de: https://www.oas.org/dil/ esp/tratados_b-32_convencion_americana_sobre_derechos_humanos.htm

Congreso de Colombia. (25 de julio del 2005). Se dictan disposiciones para la reincorporación de miembros de grupos armados organizados al margen de la ley, que contribuyan de manera efectiva a la consecución de la paz nacional y se dictan otras disposiciones para acuerdos humanitarios. [Ley 975 de 2005]. 
Cuya, E. (s.f). Las comisiones de la verdad en América Latina. Recuperado de: http:// www.derechos.org/koaga/iii/1/cuya.html

Giraldo, G. G. (2006). La CNRR :¿ Dr. Jekyll o Mr. Hyde? Por una comisión que contribuya a la efectiva reparación de los derechos de las víctimas de crímenes de guerra y de lesa humanidad en Colombia. Pensamiento Jurídico, (17), 127-146.

Gobierno Nacional y FARC-EP. (2016). Acuerdo final para la terminación del conflicto y la construcción de una paz estable y duradera. Recuperado de: http:// www.altocomisionadoparalapaz.gov.co/mesadeconversaciones/PDF/241480106030.11-1480106030.2016nuevoacuerdofinal-1480106030.pdf

Gómez Gallego, J., Herrera Vergara, J., Pinilla Pinilla, N. (2010). Informe final de la Comisión de la Verdad sobre los hechos del Palacio de Justicia. Colección textos de jurisprudencia. Universidad del Rosario. Recuperado en: http://repository.urosario. edu.co/bitstream/handle/10336/8792/Informe_comision_web.pdf?sequence=1

González, E. y Varney, H. (Ed.). (2013). En busca de la verdad. Elementos para la creación de una comisión de la verdad eficaz. ICJT. Recuperado de : https://www.ictj.org/ sites/default/files/ICTJ-Book-Truth-Seeking-2013-Spanish.pdf

Guzmán Campos, G. (1986). Reflexión crítica sobre el libro 'La Violencia en Colombia'. Pasado y presente de la violencia en Colombia. Bogotá: CEREC, 349-366.

Hayner, P. B. (2001). Unspeakable truths: Confronting state terror and atrocity. Psychology Press.

. (2006). Comisiones de la verdad: resumen esquemático. International Review of the Red Cross (862), 1-18.

Jaramillo Marín, J. (2011a). Experts and Commissions Study on Violence in Colombia. Estudios Políticos, (39), 231-258. Recuperado de: http://www.scielo.org. co/scielo.php?script=sci_arttext\&pid=S1657-63572010000200011\#n17

. (2011b). Narrando el dolor y luchando contra el olvido en Colombia. Recuperación y trámite institucional de las heridas de la guerra. Sociedad y Economía, (19), 205-228.

Junta Militar del Gobierno. (27 de mayo de 1958). Creación de la Comisión Investigadora de las Causas de la Violencia. [Decreto 0942 de 1958].

Kritz, N. J. (Ed.). (1995). Transitional justice: how emerging democracies reckon with former regimes (Vol. 1). US: Institute of Peace Press. 
Memoria Histórica de la Comisión Nacional de Reparación y Reconciliación. (2008). Trujillo, una tragedia que no cesa. Recuperado de: https://www.centrodememoriahistorica. gov.co/descargas/informes2008/informe_trujillo.pdf

Minow, M. (1998). Between vengeance and forgiveness: Facing history after genocide and mass violence. Beacon Press.

Oficina del Alto Comisionado delas Naciones Unidas. (2010). Presentación sobreComisiones de la Verdad y Justicia de Transición en evento de la Universidad Federal de Rio de Janeiro, Brasil. Recuperado de: http://acnudh.org/wp-content/uploads/2011/02/ Presentaci\%C3\%B3n-Comisiones-de-la-Verdad-Rio-octubre2010.pdf

Comisión de Superación de la Violencia. (1992). Pacificar la paz: lo que no se ha negociado en los acuerdos de paz. Recuperado de: http://observatorioetnicocecoin.org.co/ cecoin/files/pacificar_la_paz.pdf

Presidencia de la República. (25 de abril de 1991). Se crea la Comisión Gubernamental de derechos humanos para la Costa Atlántica y se señalan algunas funciones. [Decreto 1078 de 1991].

- (18 de julio de 1994). Se crea la Comisión de Derechos Humanos adscrita al Departamento Administrativo de la Presidencia de la República y se asignan algunas funciones. [Decreto 1533 de 1994].

- (20 de diciembre de 1994). Diario Oficial No. 41.639, de 20 de diciembre de 1994 . Se crea la Comisión Especial para la investigación de los hechos correspondientes al Caso número 11.007 de la Comisión Interamericana de Derechos Humanos. [Decreto 2771 de 1994].

- (15 de febrero de 1996). Se crea el Comité de impulso para la administración de justicia en relación con los hechos de Uvos, Caloto y Villatina. [Decreto 0318 de1 15 de febrero de 1996].

- (4 de junio de 1998). Se crea la Comisión para la Búsqueda de la Verdad. [Decreto 1015 de 1998].

_. (5 de abril del 2017). Se organiza la Comisión para el Esclarecimiento de la Verdad, la Convivencia y la no Repetición. [Decreto 588 de 2017].

Sánchez, G. (1988). Guerra y política en la sociedad colombiana. El Ancora Editores. 
Springer N. (2012). Sobre la verdad en los tiempos del miedo. Del establecimiento de una Comisión de la Verdad en Colombia y los desafíos para la justicia restorativa. Serie Pretextos. Bogotá: Universidad Externado de Colombia.

Teitel, R. G. (2000). Transitional justice. Oxford University Press on Demand.

Tribunal Internacional de Núremberg. (1947). Código de Núremberg. Recuperado de: http://www.bioeticanet.info/documentos/Nuremberg.pdf

Villarraga Sarmiento, A. (s.f) Posibilidades de una comisión de verdad. Recuperado de: https://www.google.com.co/url?sa=t\&rct=j\&q=\&esrc=s\&source=web\&cd

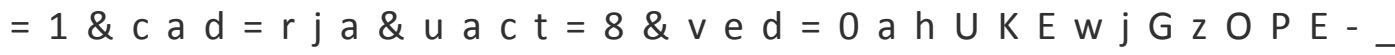
DTAhWEeCYKHZPwCQAQFggkMAA\&url=http\%3A\%2F\%2Fw1.cejamericas.

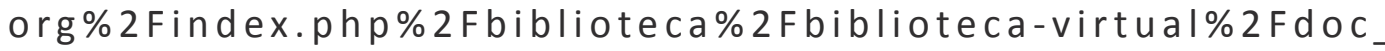
view\%2F2663-posibilidades-de-una-comisi\%25C3\%25B3n-de-la-verdad. html\&usg=AFQjCNEdcaVAtuRxolmw9W1ZPXZ2qOG_Jw 